\title{
Germanica
}

Ernst Bloch, La lutte, pas la guerre. Écrits pacifistes radicaux (1918). Traduction de l'allemand et présentation par Lucien Pelletier

Paris, Éditions de la Maison des sciences de l'homme, 2018, 170 p.

\section{Stephanie Baumann}

\section{OpenEdition}

Journals

Édition électronique

URL : https://journals.openedition.org/germanica/10366

DOI : 10.4000/germanica.10366

ISSN : 2107-0784

Éditeur

Université de Lille

Édition imprimée

Date de publication : 18 décembre 2020

Pagination : 225-227

ISBN : 978-2-913857-46-9

ISSN : 0984-2632

Référence électronique

Stephanie Baumann, «Ernst Bloch, La lutte, pas la guerre. Écrits pacifistes radicaux (1918). Traduction de l'allemand et présentation par Lucien Pelletier », Germanica [En ligne], 67 | 4e trimestre 2020, mis en ligne le 15 février 2021, consulté le 04 janvier 2023. URL : http://journals.openedition.org/germanica/10366 ; DOI : https://doi.org/10.4000/germanica.10366

Ce document a été généré automatiquement le 4 janvier 2023.

Tous droits réservés 


\section{Ernst Bloch, La lutte, pas la guerre. Écrits pacifistes radicaux (1918). Traduction de l'allemand et présentation par Lucien Pelletier}

Paris, Éditions de la Maison des sciences de l'homme, 2018, 170 p.

\section{Stephanie Baumann}

\section{RÉFÉRENCE}

Ernst Bloch, La lutte, pas la guerre. Écrits pacifistes radicaux (1918). Traduction de l'allemand et présentation par Lucien Pelletier, Paris, Éditions de la Maison des sciences de l'homme, 2018, $170 \mathrm{p}$.

1 Zu keinem Zeitpunkt, auch nicht in den ersten Kriegstagen, ließ sich Ernst Bloch von jener Kriegsbegeisterung anstecken, die beim Ausbruch des Ersten Weltkriegs die allermeisten deutschen Intellektuellen - darunter etwa auch seinen Lehrer Georg Simmel - erfasste ${ }^{1}$. In der „Bibliothèque allemande“ der Éditions de la Maison des sciences de l'homme hat Lucien Pelletier (Université de Sudbury, Kanada) anlässlich der Gedenkfeiern zum 100. Jahrestag des Kriegsendes im Jahr 2018 drei Texte von Ernst Bloch ins Französische übersetzt und unter dem Titel La lutte, pas la guerre mit einem Vorwort herausgegeben. Der Band ist ein weiterer Beitrag der "Série Philia“, in der bereits zahlreiche Texte deutschsprachiger Autoren aus der ersten Hälfte des 20. Jahrhunderts erschienen sind, beispielsweise von Walter Benjamin, Georg Simmel oder Max Horkheimer/Theodor W. Adorno.

Ernst Bloch, der die Außenpolitik des deutschen Kaiserreichs von Grund auf ablehnte, lebte seit dem Frühjahr 1917 bis zum Frühjahr 1919 mit seiner Frau Else von Stritzky in der neutralen Schweiz, wo sich damals eine Reihe deutscher Intellektueller und Schriftsteller (wie etwa Else Lasker-Schüler oder Gershom Scholem) aufhielten. Bloch 
war 1916 nach einer ersten Musterung wegen starker Kurzsichtigkeit vom Militärdienst freigestellt worden. Nach der „Schlacht an der Somme“ stand für ihn zu befürchten, dass die deutsche Armee angesichts ihrer großen Verluste auch die "Reserven“ einziehen und an die Front schicken würde. In der Schweiz schloss der damals Einunddreißigjährige im Mai 1917 zunächst sein erstes Buch Geist der Utopie ab, das ein Jahr später veröffentlicht wurde, und schrieb dann regelmäßig für die Berner Freie Zeitung, die sich als „unabhängiges Organ für demokratische Politik“ verstand. Diese Zeitung, welche die bürgerlich-demokratische, nicht aber sozialistisch oder marxistisch ausgerichtete Opposition versammelte, war Träger der politischen Ideen Woodrow Wilsons und Bloch publizierte hier neben Autoren wie Hugo Ball, Iwan Goll oder Annette Kolb bis Dezember 1918 über einhundert Artikel zur Unterstützung der Entente.

In den drei Texten des vorliegenden Bandes, die zwischen Juni und September 1918 erschienen, liest Bloch die Geschichte Preußens als Vorgeschichte des Ersten Weltkriegs und kämpft publizistisch für einen schnellen Frieden, für ein demokratisches und auch sozialistisches Deutschland. Der erste Text von Juni 1918 über eine potenzielle Niederlage der Mittelmächte, „Schadet oder nützt Deutschland eine Niederlage seiner Militärs?“, ist der Versuch, auf die revolutionäre Situation in Deutschland Einfluss zu nehmen. Nachdem die USA im April 1917 dem Krieg beigetreten waren, war mit der Niederlage der Mittelmächte zu rechnen. Bloch begrüßt diese Perspektive, sieht er doch darin die Chance für Deutschland, sich der Herrschaft der preußischen Junker zu entledigen und eine Demokratie zu errichten, notwendige Voraussetzung für einen dauerhaften Frieden. Bloch unterstreicht nicht nur die ökonomischen und politischen Vorteile, sondern auch den sittlich-seelischen Gewinn eines schnellen Kriegsendes für die Bevölkerung: Die Wortbrüchigkeit der deutschen Kriegs-Diplomatie in Brest-Litowsk hätte den moralischen Ruin des deutschen Volkes nach sich gezogen, bis in die Privatsphäre hinein sei jeglicher „Rest von Güte und Rechtsgewissen" spürbar abhandengekommen. Nach der gescheiterten Julioffensive des Jahres 1918 schreibt er im September nun in Erwartung eines baldigen Waffenstillstands sein „Vademecum für heutige Demokaten“, einen Text, der ebenso wie der dritte Artikel nicht in die Suhrkamp-Gesamtausgabe der Bloch'schen Werke aufgenommen wurde. Beide wurden erstmalig Mitte der 1980er Jahre in einem Band mit politischen Schriften bei Suhrkamp erneut herausgegeben (Kampf, nicht Krieg. Politische Schriften 1917-1919, Suhrkamp 1985, hrsg. von Martin Korol). Im „Vademecum“ steht die Frage nach der Kriegsschuld sowie der Kriegsursachen im Vordergrund. Blochs Haltung unterscheidet sich nicht nur von der radikalpazifistischen Argumentation Stefan Zweigs, der dazu aufrief, auch die „westlichen“ Kriegsideen zu ächten, sondern er richtet sich auch gegen die Positionen von Lenin und Trotzki, die auf den Konferenzen von Zimmerwald und Kiental vertreten wurden. Bloch deutet den Krieg nicht als Höhepunkt einer notwendigen Entwicklung des Kapitalismus, sondern erklärt ihn aus der deutschen Geschichte, deren Sonderentwicklung innerhalb Europas für ihn bereits früh, mit der Reformation 1517, einsetzt. Ihm zufolge sind nicht alle imperialistischen Mächte gleichermaßen für den Kriegsausbruch verantwortlich. Er sei mit ökonomischem Kalkül nicht zu erklären, wurzele er doch nicht im kapitalistischen Imperialismus, sondern im puren Machtwillen: „[D]ie eigentliche Bewegung zum Krieg und seine Erhaltung bleibt der abstrakte Machtstaat an sich, die Versachlichung, Entpersönlichung, totale Organisierung, das Selbstleben des menschenfremden, abstrakt machthaften Staatsapparates, preußisch-österreichischen Obrigkeitsstaates “" 
Er spricht sich damals gegen die Option aus, sich im Kampf gegen den preußischen Militarismus den Bolschewiki anzuschließen, und warnt in „Das falsche Geleise Zimmerwalds“ im November 1918 - anders als in den Jahren, als er sich zum Kommunismus bekennt - vor der Möglichkeit der Errichtung eines autoritären Staates in Russland: „Sozialismus ohne weitgehende Auflockerung der Verbände, ohne weitgehende Demokratie auch des Einzellebens ist lediglich ein Preußentum anderer Ordnung “3. Den dritten Text mit dem Titel „Über einige politische Programme und Utopien der Schweiz" gab der Sozialökonom Emil Lederer für das Archiv für Sozialwissenschaft (Heidelberg) bei Bloch in Auftrag: er präsentiert hier antimilitaristische Positionen, von katholisch-internationalen bis hin $\mathrm{zu}$ sozialanarchistischen Trägern in der Schweiz.

4 Alle drei Artikel sind als tagespolitische Interventionen zu lesen, die vornehmlich mit Blick auf die Geschichte des Pazifismus von Interesse sind, tragen sie doch dazu bei, einen Eindruck von der Vielfalt der damals vertretenen Positionen zu vermitteln. Wie Lucien Pelletier in der Einleitung zeigt, sind die Texte jedoch auch für all jene mit Gewinn zu lesen, die sich für Blochs Geschichtsphilosophie interessieren, sind hier doch bereits zentrale Motive späterer Schriften angelegt: im Zusammenhang mit den Utopien in der Schweiz ist etwa von der Apokalypse die Rede, als Figur einer radikalen Erneuerung der Welt ${ }^{4}$. Auch findet sich in den Texten aus dem Sommer 1918 bereits das Konzept der ,Ungleichzeitigkeit' als Kennzeichen der Moderne, das Ernst Bloch in Erbschaft dieser Zeit (1935) weiter ausführen wird.

\section{NOTES}

1. Vgl. Daniel Weidner, „Innere Wandlung und Selbstmord Europas: Georg Simmel im Ersten Weltkrieg“, in: Hans Richard Brittnacher/Irmela von der Lühe (Hrsg.), Kriegstaumel und Pazifismus. Jüdische Intellektuelle im Ersten Weltkrieg, Frankfurt a.M., Peter Lang, 2016, S. 161-178, hier S. 165f.

2. Ich zitiere nach Ernst Bloch, „Vademecum für heutige Demokraten“, in: Kampf, nicht Krieg. Politische Schriften 1917-1919, hrsg. v. Martin Korol, Frankfurt a.M., Suhrkamp, 1985, S. 475-530, hier S. 511.

3. E. Bloch, „Das falsche Geleise Zimmerwalds“, in: ebd., S. 388-390, hier S. 390.

4. E. Bloch, „Über einige politische Programme und Utopien in der Schweiz“, in: ebd., S. 532-559, hier S. 559. 